\title{
DEMOCRACIA, FASCISMO Y POPULISMO: SOBRE EL ESPACIO POLIITICO ANTIPERONISTA ${ }^{1}$
}

\section{DEMOCRACY, FASCISM, POPULISM: ABOUT THE ANTI-PERONISM POLITICAL SPACE}

\author{
Nicolás Azzolini*
}

\begin{abstract}
RESUMEN
Enmarcado en los desarrollos recientes de la teoría política contemporánea sobre la categoría de populismo, el presente trabajo es un intento de problematizar sobre dicha categoría y sus posibilidades de extenderla al análisis de fenómenos, que no han sido identificados como tales. En tal sentido, se presenta una serie de apuntes sobre la conformación del espacio político antiperonista.
\end{abstract}

PALABRAS CLAVE: ARGENTINA * TEORÍA POLÍTICA * DEMOCRACIA * PUEBLO * ESTADO

\section{ABSTRACT}

Framed within recent developments in contemporary political theory on the category of populism, this paper is an attempt to problematize on that category and their ability to extend the analysis of phenomena that have not been identified as such. In that sense, this work presents a series of notes on the formation of the anti-Peronist political space.

KEYWORDS: ARGENTINA * POLITICAL THEORY * DEMOCRACY * PEOPLE * STATE

1 Una versión preliminar de este trabajo fue presentada en el IX Congreso Nacional de Ciencias Política, Sociedad Argentina de Análisis Político. Universidad Nacional del Litoral y Universidad
Católica de Santa Fe, del 19 al 22 de agosto de 2009.

* Universidad Nacional de San Martín, Argentina. nicolasazzolini@gmail.com 
I

El peronismo es un fenómeno político que recibió una pluralidad de significaciones ${ }^{2}$. Así, la diversidad de sentidos que median el hecho peronista va desde su descalificación como un caso asociado con el fascismo europeo, hasta las intervenciones que desde las ciencias sociales $y$ humanas lo definieron como un dato específico de los populismos latinoamericanos de mediados del siglo Xx. En cambio, el antiperonismo, si bien ha sido caracterizado - principalmente por los actores que se identificaron como tales- como el espacio político que aglutino a los sectores democráticos de la sociedad argentina que se oponían al nazi-peronismo, en tanto objeto de estudio recibió un tratamiento residual y algunas veces reactivo. Es decir, aparece tratado de forma subordinada al supuesto actor central del período y suele ser presentado como una reacción a la emergencia del peronismo.

Ahora bien, si se señala que el propio peronismo es un fenómeno polisémico, cabe aclarar que distinta no ha sido la suerte de muchas de las categorías mediante las cuales se pretendió definir su especificidad. Dentro de ellas, un ejemplo notable es la de populismo. Aunque ampliamente usada para describir una gran multiplicidad de movimientos, es escasa la claridad conceptual que permite distinguir al populismo de otros tipos de movimientos políticos. Frente a un terreno conceptual que aparece ambiguo e indeterminado, ya sea en relación a sus postulados políticos como a los referentes empíricos sobres los cuales se aplicó la categoría, generalmente, el populismo recibió un carácter peyorativo, fue asociado a un exceso político. En tal sentido, dicho carácter muchas veces se ha correspondido con la identificación del peronismo como un fenómeno aberrante en los intentos de consolidación de la Argentina como República. Ante dicho marco, desarrollos recientes en la teoría política contemporánea se propusieron rescatar al populismo del lugar marginal que ocupa en los discursos académicos. Dentro de ellos, uno de los referentes más destacados es el aportado

Sobre el particular, véase de Ípola, 1989. por Ernesto Laclau. Para este autor, el populismo es una lógica social que atraviesa una variedad de fenómenos.

De tal modo, el presente artículo será un intento de problematizar en torno a la categoría de populismo y sus posibilidades de extenderla al análisis de fenómenos que no han sido identificados como tales. Para ello, en primer lugar, se valdrá de lo dicho sobre el antifascismo argentino y su relación con el peronismo. En segundo lugar, se repasará algunas de las lecturas que tomaron al fenómeno peronista como objeto de estudio. Finalmente, se buscará posibles conexiones entre los apartados que dan cuerpo al trabajo, con el fin de realizar una serie de apuntes sobre la conformación del espacio político antiperonista.

\section{II}

Los procedimientos democráticos liberales han sido un reclamo recurrente en la historia argentina de los dos últimos siglos. Particularmente, las demandas se han constituido en torno a los cuidados como al restablecimiento de dichos procedimientos. Así, por ejemplo, el antifascismo argentino se conformó como una tradición política defensora de los valores democráticos liberales, en la primera mitad del siglo Xx. En tal sentido, Andrés Bisso (2007) - al trabajar sobre las condiciones de posibilidad, esplendor y ocaso del antifascismo en Argentina - analiza la capacidad de movilización que tiene la apelación antifascista en relación a los reclamos democráticos. Dicha capacidad, según el autor, estuvo vinculada con dos mitos que el antifascismo argentino supo labrar en relación al contexto internacional: la amenaza nazifascista y el fascismo criollo.

En cuanto al primero, su apelación argüía el constante peligro de que los totalitarismos europeos - básicamente Alemania e Italiainvadieran o dominaran el país y denunciaba los peligros de las acciones de espionaje y sabotaje, en manos de las embajadas y minorías extranjeras instaladas en la Argentina.

En correspondencia con los peligros de dominación externa, el mito del fascismo criollo hacia alusión a la existencia de nativos cómplices con los regímenes totalitarios. El mote 
servía para denostar a personas concretas y a los referentes de promover el fascismo local, los cuales fueron cambiando a través del tiempo. De tal modo, presidentes surgidos por procedimientos legales, fraudulentos o propios a los gobiernos de facto serían acuñados con el rotulo de fascistas criollos.

Así, aunque no en términos de Bisso, el antifascismo argentino se articuló en torno a la restauración de una democracia procedimental $y$ al encuadre en el campo de los que se definían como democráticos a nivel internacional. En palabras del autor, constituiría:

... una tradición cultural capaz de mutar con el transcurso del tiempo y esparcirse, flexible y potencialmente, tanto para definir el ropaje del enemigo al que se buscaba atacar como para conferir a los grupos unidos heterogéneamente bajo esa apelación cierto enfoque en común con el que comulgar (Bisso, 2007: 21).

En tal sentido, este autor señala la figura de Juan D. Perón como emblemática en el derrotero histórico del antifascismo argentino. Ya que frente al desenlace final de la Segunda Guerra Mundial y al ascenso del joven coronel, en el seno del gobierno militar, para los democráticos Perón logró encarnar todos los males del fascismo.

Sin embargo, según Bisso:

...[e]stas derivaciones de la lucha antifascista y democrática no deberían ser vistas, a nuestro entender, como el mero resultado de la imposición preferencial de móviles sectarios o mezquinos. Deberíamos considerar, más prudentemente, que en la práctica cotidiana de los dirigentes, las proposiciones patrióticas, los resultados políticos y los beneficios partidarios -e incluso, las posibilidades de promoción individual- eran comprendidos como parte de una misma estrategia destinada a 'salvar al país del fascismo' y en la que la eficaz consecución de este fin primordial no podía traer más que — conjuntamente- beneficios absolutos al movimiento democrático y utilidades relativas a los dirigentes $y$ a los partidos que mejor lo supieran promover (2007: 18).

Finalmente, el fracaso electoral de la Unión Democrática ${ }^{3}$ marcaría la declinación del antifascismo como apelación política nacional, en cuanto "había generado en su último acto que los demócratas confiaran demasiado en ella debido al esplendor con el que había llegado luego de arduas disputas en ambientes difíciles de fraude, estado de sitio y dictadura" (Bisso, 2007:92).

\section{III}

Sin embargo, más allá de las efervescencias que habría despertado el surgimiento del peronismo en los diferentes espacios políticos contemporáneos a dicho suceso, tal como suele remarcarse, Gino Germani fue uno de los primeros en sostener — desde el ámbito académico- que el peronismo era un fenómeno distinto al fascismo europeo. El argumento de Germani ${ }^{4}$ es que dicha experiencia política habría sido un movimiento policlasista asentado sobre la alianza entre la nueva burguesía industrial, el viejo y nuevo proletariado y los militares, cuyo logro consistió en incorporar a las clases bajas en la vida política nacional. Así, tanto la composición como las metas del

3 Coalición electoral conformada por los partidos políticos Socialista, Comunista, Radical y Demócrata Progresista, para las elecciones presidenciales del 24 de febrero de 1946, cuya fórmula estuvo encabezada por los radicales José P. Tamborini y Enrique Mosca. Finalmente, la fórmula Perón-Quijano se impuso por el 55\% contra el 45\% obtenido por los candidatos de la Unión Democrática. Al respecto, véase Luna, 1984.

4 Si bien, Germani ha desarrollado sus tesis sobre el fenómeno peronista en una pluralidad de trabajos (Germani, 1965, 1973, 2003), el presente artículo se basará principalmente en la última de estas obras. El motivo de dicha selección no es arbitrario, en cuanto allí no solo se recopilan las principales hipótesis del pensador italiano sobre el tema, sino que incluye todas sus reformulaciones $y$ respuestas a las críticas que le han realizado a su obra. Para profundizar en las críticas a los trabajos de Germani véase Halperín Donghi, 1975; Murmis y Portantiero, 1973; Laclau, 1978 y Torre, 1990. 
peronismo harían de este un fenómeno distinto al fascismo. En sus palabras:

... el peronismo temprano (1945-1955), que emergió de la movilización primaria de las clases bajas, fue percibido por mucha gente como una forma de fascismo ["fascismo de izquierda"], mientras que las clases medias pertenecían a una coalición que proclamaba principios democráticos y liberales (...), en realidad, la situación era bastante diferente: la meta del peronismo no era desmovilizar a las clases bajas [la razón de ser del fascismo, y cualquiera hayan sido sus limitaciones en relación con las reformas estructurales, su efecto fue precisamente el contrario: la incorporación a la vida política nacional de aquellas masas que, hasta entonces, habían permanecido en un lugar marginal o habían sido desmovilizadas por la restauración conservadora de la década de 1930 (Germani, 2003: 247).

De tal modo, Germani presenta al peronismo como una forma de autoritarismo moderno, donde si bien encuentra relaciones con el fascismo europeo, el caso argentino se caracterizaría por ser un movimiento populista nacional. Veamos con mayor detenimiento las claves analíticas de su explicación.

En su intento por estudiar los vínculos entre la emergencia de regímenes autoritarios y el proceso de modernización socio-económica, Germani se basa principalmente en la idea de movilización social ${ }^{5}$, el papel de las clases

5 La movilización social entra en juego cuando se desintegran los antiguos compromisos y lealtades políticas, psicológicas y sociales que ponen en disponibilidad a diferentes sectores de la población para acceder a las nuevas formas de comportamiento. Así, "la movilización es un ciclo, que comienza con una integración original en un tipo de estructura social dada y termina con la reintegración en un nuevo tipo de estructura social, atravesando estadios de desintegración, de disponibilidad $y$ de preparación para nuevas forma de participación" (Germani, 2003: 53). Sin embargo, es importante remarcar la distinción que el autor italiano señala entre movilizaciones primarias y movilizaciones secundarias. Donde, "la movilización secundaria sucede a menudo como una sociales y en las particularidades de estratificación propias al inicio de una movilización social para comparar al fascismo con el populismo nacional.

En tal sentido, el fascismo clásico se presenta como una de las formas que puede asumir el autoritarismo moderno en relación con las contradicciones que se producen hacia el interior de la sociedad por causa del proceso de secularización creciente. En cambio, el populismo nacional - como otra forma que puede asumir el autoritarismo moderno- representa una vía de movilización primaria basada, generalmente, en la alianza del proletariado urbano $y$ los nuevos sectores provenientes de la burguesía industrial. De esta forma, Germani define al populismo como un movimiento policlasista que "tiende a negar cualquier identificación con o cualquier clasificación en una dicotomía de derecha/izquierda" (2003: 114). Así, el populismo logra incluir dentro del movimiento, componentes contradictorios como:

... demandas socialistas (o por lo menos, un reclamo de justicia social), la defensa vigorosa de la pequeña propiedad, acompañado por la afirmación de los derechos de la gente común como contradictorios a los grupos poderosos privilegiados, usualmente considerados hostiles al pueblo y a la nación (Germani, 2003: 114).

En suma, si bien el fascismo como el populismo nacional son dos de las alternativas dentro de la clasificación de regímenes autoritarios propios del proceso de modernización socio-económica, las particularidades en la estratificación social de Europa y América Latina $y$ la preeminencia de diferentes clases sociales en el inicio de las movilizaciones sucedidas, harán de ambos regímenes dos experiencias distintas.

Finalmente, otro punto a señalar en la obra de Germani es la relación entre los tipos de movilización primaria y secundaria que se dieron en Argentina a mediados de 1940. Según este autor italiano, en aquel entonces, pueden

reacción a la movilización primaria de sectores excluidos o parcialmente marginales" (2003: 55). 
encontrarse dos masas movilizadas, la primera, era una movilización primaria y estaba encabezada principalmente por las nuevas clases trabajadoras; en cambio, la segunda, era una movilización secundaria encabezada por la clase media, puesto que los sectores que la componían ya estaban integrados en la sociedad argentina. En tal sentido, Germani remarca que:

...[1]a mayor parte de los investigadores ha subrayado la movilización de las clases bajas. Sin embargo, la movilización política de las clases medias también es importante para comprender el proceso. El conflicto entre las clases y su polarización fueron el resultado de esta doble movilización y de las formas ideológicas que asumieron. Es útil para evaluar tanto el triunfo del populismo nacional como el desarrollo político durante $y$ después del primer gobierno peronista (2003: 196).

A partir de lo expuesto, se ha visto como la lectura académica de Germani rechaza las consideraciones que definen al peronismo como la encarnación del fascismo en las tierras argentinas. Para ello, valiéndose de la noción analítica de movilización social y el papel de las clases en la estratificación social en que emerge el peronismo, define a este último como un fenómeno populista nacional.

\section{IV}

Ahora bien, si la presentación del argumento de Germani sobre el peronismo nos trasladó desde la noción de fascismo a la del populismo. Dicho desplazamiento nos deja en un terreno oscuro e indeterminado, en cuanto si uno rastrea la literatura en torno a la especificidad del populismo suele encontrar el llamado de atención sobre la vaguedad del término y la vacilación del objeto al cual se refiere. En tal sentido, la producción del teórico argentino Ernesto Laclau resulta un referente indiscutible de los intentos que buscan superar la "anarquía conceptual" que implica dicho concepto. Para Laclau, el populismo debe ser entendido como una forma de articulación política y no como un movimiento político o una ideología específica. Si bien, al igual que Germani identifica al peronismo con el populismo, al presentarlo como una forma de articulación, sus argumentos disienten con los esgrimidos en la caracterización dada por el sociólogo italiano. En palabras de Laclau, el peronismo como dato populista en la historia argentina habría logrado articular:

... el conjunto de las interpelaciones que expresaban la oposición al bloque de poder oligárquico —-democracia, industrialismo, nacionalismo, antiimperialismo-, condensarlas en un nuevo sujeto histórico y desarrollar su potencial antagonismo enfrentándolo con el punto mismo en el que el discurso oligárquico encontraba su principio de articulación: el liberalismo. Todo esfuerzo ideológico peronista en esta etapa estará destinado a desligar al liberalismo de sus últimos vínculos con un campo connotativo democrático y a presentarlo como una pura y simple cobertura de los intereses de la clase oligárquica (1978: 221).

Es decir, partiendo de la idea althusseriana de interpelación, para Laclau, el peronismo logró obtener la hegemonía en el terreno ideológico, en tanto habría articulado diferentes discursos que estaban presentes en el contexto histórico en que surge el peronismo y oponerlos al bloque oligárquico. En tal sentido, sostiene Laclau:

... [n]inguna otra ideología populista latinoamericana se constituyó a partir de la articulación de interpelaciones más dispares; ninguna otra tuvo tanto éxito en el esfuerzo por transformarse en denominador común del lenguaje popular-democrático de las masas; ninguna otra, finalmente, fue articulada a tan diversos discursos de clase (1978: 206).

De tal modo, hablar del populismo como forma de articulación política implica considerarlo como una categoría ontológica y no óntica. Esto es, que su significación no puede 
hallarse en ningún movimiento ni contenido político o ideológico, "sino en un particular modo de articulación de cualesquiera sean los contenidos sociales, políticos o ideológicos" (Laclau, 2005b: 27). Por lo tanto, como se señala, para este teórico argentino, el populismo es una lógica política y no un tipo de movimiento identificado con una base social particular.

Ahora bien, Laclau sostiene que la referencia al pueblo es un rasgo común en la gran diversidad de usos del término. Precisamente, es dicha referencia al pueblo la que ocupa un lugar central en su propia concepción del populismo. Para ello se explicarán los supuestos generales de su propuesta ${ }^{6}$.

Básicamente, tres serían las condiciones estructurales que caracterizan una lógica de articulación populista:

... la unificación de una pluralidad de demandas en una cadena equivalencial; la constitución de una frontera interna que divide a la sociedad en dos campos; la consolidación de una cadena equivalencial mediante la construcción de una identidad popular que es cualitativamente algo más que la simple suma de los lazos equivalenciales (Laclau, 2005a: 12).

$6 \quad$ Aunque la definición de populismo como la presentación de las interpelaciones popular-democráticas que se oponen al bloque dominante constituye la primera aproximación de Laclau al tema; no obstante, el nudo argumental en torno a la construcción del pueblo como rasgo fundamental se mantiene en la misma senda interpretativa pese a las modificaciones que ha introducido en su teoría a lo largo de los años. Él mismo lo ha señalado en varias oportunidades, por ejemplo, recientemente ha vuelto a sostener la continuidad en su línea de pensamiento en una serie de entrecruces con Žižek: "en él - haciendo referencia a su primer texto- se formulan por primera vez las líneas generales de un enfoque teórico que he mantenido consecuentemente y que ha culminado recientemente en La razón populista" (Laclau, 2008: 65). Es decir, la idea de construcción del pueblo como articulación que establece una frontera que lo separa del poder, sigue siendo un rasgo fundamental en su concepción del populismo. De tal modo, para presentar sus argumentos se remite indistintamente a la pluralidad de obras de Laclau sobre el tema.
Esto es, una demanda ${ }^{7}$ no respondida por la instancia de decisión, la cual permite potencialmente que los ciudadanos demandantes establezcan algún tipo de solidaridad con sectores que tienen demandas distintas. Este tipo de solidaridad es lo que Laclau denomina lógica de equivalencia, ya que las demandas insatisfechas, dada su relación de negatividad con un otro - con la autoridad decisoria - entran en relación entre $\mathbf{s i}^{8}$. En tal sentido, en el populismo de Laclau, las demandas que se reagrupan sobre la base negativa de su insatisfacción tienden a desestabilizar el orden instituido. De ahí la caracterización del populismo por su condición de ruptura. De este modo, dichas demandas serán presentadas como demandas populares, ya que mediante su articulación equivalencial constituyen una subjetividad social más amplia fragmentando a la sociedad en dos espacios políticos antagónicos. Así, en una articulación populista, el pueblo resultante de la división interna de la sociedad es menos que el total de los miembros de la comunidad, es una parte que pretende ser la única totalidad legítima. Por eso, la distinción terminológica entre populus - como totalidad de ciudadanos-y plebs - como los menos privilegiados-. Sin embargo, Laclau considera necesario algo más para concebir al pueblo del populismo: "necesitamos una plebs que reclame ser el único populus legítimo" (Laclau, 2005a: 108)9.

$7 \quad$ En La razón populista, Laclau sostiene que las demandas son las unidades sobre las cuales debe comenzar el análisis, en tanto es la forma elemental de la construcción del lazo social. Así, Laclau distingue entre demandas democráticas y demandas populares, donde las primeras, buscan su satisfacción de manera no conflictiva, en cambio, las segundas, dado su carácter antagónico dividen a la sociedad en dos campos opuestos.

8 Uno de los ejemplos que Laclau da, es la relación equivalencial entre la demanda de vecinos de un barrio que reclaman la extensión del recorrido del transporte urbano junto a demandas por mayor seguridad, mejoras en la provisión de agua, vivienda, etc. En todos los casos es la instancia gubernamental la que imposibilita la satisfacción de las mismas

9 Dado que en el populismo, la parte que se identifica con el todo quiebra la armonía social, cabe 
Ahora bien, en el surgimiento del pueblo es necesaria la unificación simbólica de la cadena de equivalencia, esto es, la construcción de una identidad popular cualitativamente mayor a la simple adición de lazos equivalenciales. Por lo que la división interna en lo social se establece entre dos grupos definidos: el pueblo y el poder. Lo cual implica que el surgimiento del populismo solo puede tener lugar ante la construcción discursiva de un enemigo como figura antagónica que impide la constitución de la identidad popular. Así que, la equivalencia no puede hallarse en ningún aspecto positivo subyacente a todas las demandas, sino en la oposición que ellas tienen respecto al poder que se encuentra cruzando la frontera.

No obstante, tal como se señala al comienzo, dicho proceso no es el resultado de un desarrollo ideológico o de un movimiento político, sino de una práctica articulatoria. Por eso, Laclau dirá en oposición a los enfoques básicos sobre el populismo: "Mi argumento es que la construcción del pueblo como actor social colectivo requiere extender la noción de populismo a muchos movimientos y fenómenos que no han sido identificados con esa denominación” (2008: 56).

Como corolario de lo expuesto, se ve que el peronismo pasó de ser connotado como un movimiento fascista a ser definido como uno de tipo populista. Es decir, la lectura del antifascismo argentino realizada por Bisso dio pié para presentar la caracterización del peronismo como una solución populista nacional en la lectura de Germani. Así, se adentra en un terreno ambiguo e indeterminado, la propuesta de Laclau permitiría abrir nuevas posibilidades interpretativas con la noción de populismo.

Ahora, el entrelazado de los autores presentados no agota sus posibilidades de

señalar el paralelo con Rancière (1996). Es decir, la plebs sería el demos entendido como lo múltiple idéntico al todo, como la parcialidad social que se presenta como la totalidad de la comunidad. Donde, en ambos casos, la pretensión de representar la totalidad se liga al accionar de la política como ruptura de lo social. conexión en el desplazamiento que va desde el fascismo al populismo. En tal sentido, se podría emprender el intento de rastrear afinidades interpretativas en posturas teóricas y epistemológicas que se postulan disímiles. Por ejemplo, buscar semejanzas en las explicaciones de Germani y Laclau sobre el populismo, a partir de las nociones de movilización y articulación. Si el sociólogo italiano presentaba a la movilización social como el proceso mediante el cual se incorpora en una nueva estructura a diferentes sectores sociales, dada la desintegración de los compromisos y lealtades políticas, sociales y psicológicas preexistentes; se podría preguntar cuán lejos está la idea de articulación como establecimiento de lazos solidarios entre una pluralidad de demandas insatisfechas, dada la desarticulación de los elementos constitutivos de un discurso hegemónico dominante ${ }^{10}$. Donde, a su vez, el populismo (= peronismo) lograría, en términos de Germani, incluir dentro del movimiento, componentes contradictorios como la demanda socialista de justicia social y la defensa vigorosa de la pequeña propiedad, o en términos de Laclau, incluir dentro de sí las interpelaciones más dispares.

Sin embargo, existe una diferencia fundamental y se da en torno al statu ontológico de la noción de clases. En Germani el populismo moviliza clases sociales preconstituidas. En cambio, para Laclau, es una lógica articulatoria que constituye a las clases como tales, más aun, produce la construcción discursiva del pueblo como actor social colectivo. Precisamente, la idea de clases como realidad objetiva era lo que permitía a Germani diferenciar al populismo del fascismo cuando interpreta la especificidad constitutiva del peronismo. Por el contrario, para el teórico argentino, el populismo no estaba identificado con una ideología o movimiento específico, sino con el modo

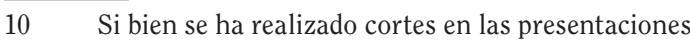
de Germani y Laclau por cuestiones funcionales al desarrollo de nuestros argumentos, en relación a la movilización y articulación, se podría continuar la búsqueda de similitudes, a partir de la figura del líder y la idea de lealtades y compromisos psicológicos en Germani con la noción de afecto introducida por Laclau en La razón populista. 
en que se produce la constitución del pueblo en oposición al poder.

En todo caso, el intento de rastrear afinidades interpretativas en las posturas de Germani y Laclau, podría llegar a caer en un trabajo minucioso y en cierto sentido particularista - no por ello poco atractivo $y$ fructífero-; en cuanto se limitaría a reducir la búsqueda de ciertas diferencias y semejanzas en torno a una categoría específica, en la propuesta de solo dos de los autores aquí presentados. Sin embargo, si se vuelve sobre las páginas que llevaron desde el fascismo al populismo, se encuentra una conexión que puede resultar de carácter más general. Dicha generalidad estaría determinada tanto por la posibilidad de jugar con Bisso, Germani y Laclau, como así también permite borrar ciertos límites disciplinarios en los cuales se inscriben los tres autores mencionados.

Según Bisso, la capacidad de mutar que tuvo el antifascismo le permitió tanto "definir el ropaje del enemigo al que se buscaba atacar como conferir a los grupos unidos heterogéneamente bajo esa apelación cierto enfoque en común con el que comulgar" (2007: 21). De tal modo, el desplazamiento de los límites de la tradición antifascista posibilitaba reasignar el mote de fascista criollo a lo largo de los años hasta llegar a su figura emblemática: Perón. Por ello, el peronismo resultó un momento cumbre en la definición del enemigo común, permitiendo incluir dentro de la tradición antifascista a una pluralidad de grupos de la sociedad argentina. Tal inclusión articularía una heterogeneidad de sectores insatisfechos que reclamaban ante el Gobierno de la Revolución, la restauración de los procedimientos democráticos liberales.

Ahora, si bien la tradición antifascista recorre con trascendencia la historia argentina a partir de la década de 1930, podría plantearse hasta qué punto el ascenso de Perón en el seno del gobierno revolucionario, no pasó a jugar un papel central en la conformación de un espacio político opositor más amplio. Es decir, si no es la misma figura de Perón la que se constituye como el exterior en la construcción de un espacio político antiperonista, en donde la dicotomía estructurada en torno al par fascismo-antifascismo resultaría tan solo uno de los principios de lectura en la constitución de la nueva identidad política. Ya que, podría pensarse en los frentes de disputas entablados hacia el interior del propio régimen militar entre Perón $y$ sectores de las fuerzas que se pronunciarían antiperonistas ${ }^{11}$, también en los conflictos alrededor de las políticas sociales ligadas a la Secretaría de Trabajo y Previsión. Así, la corporización casi perfecta que Perón representaba para el antifascismo, según señalaba Bisso, podría inscribirse en el proceso de transformación que vivieron las identidades políticas existentes y que se tradujo en la dicotomización del espacio político nacional en los campos peronista y antiperonista. Es decir, cabría considerar esa visión de encarnación "plena" del mote de fascista criollo como uno de los principios de lectura en la construcción del espacio político antiperonista; principalmente, ligado a las demandas de restauración de una democracia procedimental $y$ al encuadre en el campo de los que se definían como democráticos a nivel internacional. Justamente, "batir al naziperonismo" fue uno de los lemas con los cuales la Unión Democrática se lanzó en su campaña electoral para las elecciones presidenciales de 1946. Donde la consigna permitía tanto, definir de nazifascistas a todos aquellos que quedaban afuera de la Unión Democrática así como, cobijar dentro de sí una pluralidad de partidos políticos. En tal sentido, un folleto de los comunistas argentinos logra condensar y reflejar los males que el espacio político antiperonista encuentra en Perón dos meses antes de las elecciones presidenciales. Tales eran las palabras en uno de sus segmentos:

En este momento estamos librando con retraso nuestra batalla contra el fascismo, y su variante nacional, el peronismo. Por eso, las próximas elecciones, aún en el caso de que se realicen con ciertas garantías, no serán elecciones ordinarias, comunes, sino una batalla decisiva de la gran lucha patriótica que sostiene el pueblo argentino para librar su país de

11 Sobre el particular, véase Potash (1969). 
las garras del nazifascismo. Tenemos que combatir a un enemigo astuto, maniobrero, hábil en intrigas y provocaciones de toda especie, capaz de los procedimientos más aviesos y más criminales para conseguir sus objetivos (...) Por eso los nazi-peronistas han lanzado y lanzan la desafiante consigna de: 'reviente quien reviente, Perón será presidente', $y$ esta otra: 'triunfaremos en las elecciones caiga quien caiga y cueste lo que cueste'. ¿Cuál es el significado de tales consignas? El de preparar el clima necesario para que los fascistas puedan imponerse por la fuerza contra la voluntad del pueblo (Citado en Peña, 1986: 11-12).

Sin embargo, deberíamos preguntarnos cómo es posible explicar la constitución de un espacio político antiperonista, si habrán sido las apelaciones de la tradición antifascista las que instituyen los marcos de sentido en la campaña electoral. Precisamente, la heterogeneidad de grupos y sectores que según Bisso, se incluían dentro de la tradición antifascista, junto con otros sectores que se opusieron a Perón en las elecciones de 1946, establecerían un proceso hegemónico hacia el interior del emergente campo antiperonista. Así, los comunistas - seguidos por los socialistas - habrían sido los que bajo el principio de lectura fascismoantifascismo logran fijar ciertos sentidos compartidos en la constitución del espacio político opositor.

De tal modo, la rearticulación de los diferentes sectores que se opusieron a Perón, fueron inscritos en un discurso político que vino a dividir al campo social en dos polos antagónicos, dígase: peronismo-antiperonismo, fascismo-antifascismo, democráticos-naziperonistas, etc. A su vez, se podría considerar que la disyuntiva democracia-fascismo funciona como una frontera política que fijaba los límites respecto al campo político peronista y establecía una cadena de solidaridades que posibilitaba la inclusión, hasta de los sectores conservadores en el campo de los democráticos. Por ello, resulta posible entender la articulación de diferentes partidos políticos y sectores opositores bajo la coalición electoral de la Unión Democrática. Precisamente, según Laclau, se podría hablar de la creación de una lógica de equivalencia, en tanto distintas demandas insatisfechas comenzaron a relacionarse en oposición al candidato oficial. Entonces, siguiendo los lineamientos de Laclau, se cuestiona hasta qué punto la oposición a Perón y a sus medidas como funcionario del gobierno revolucionario, no es una dimensión central en la formación de una cadena equivalencial de demandas insatisfechas más amplia. En otras palabras: ¿no implican la construcción de un pueblo? Aquí, se podría volver sobre las palabras de Bisso, en torno a las derivaciones en la tradición antifascista, en cuanto remarcaba que las trasformaciones de la lucha antifascista y democrática no eran el resultado de móviles sectarios y mezquinos, sino:

... que en la práctica cotidiana de los dirigentes, las proposiciones patrióticas, los resultados políticos y los beneficios partidarios -e incluso, las posibilidades de promoción individual- eran comprendidos como parte de una misma estrategia destinada a 'salvar al país del fascismo'.

[Más aún, teniendo en cuenta que]

la eficaz consecución de este fin primordial no podía traer más que - conjuntamente- beneficios absolutos al movimiento democrático y utilidades relativas a los dirigentes $y$ a los partidos que mejor lo supieran promover (Bisso, 2007: 18).

Resumiendo, según Laclau, si para la emergencia del pueblo populista era necesaria: 1) la unificación de una serie de demandas insatisfechas en una cadena de equivalencias. En este caso se podría pensar en los reclamos para el Gobierno de la Revolución referentes al restablecimiento de los procedimientos democráticos liberales, como las disputas en el interior de las Fuerzas Armadas y las suscitadas por las políticas sociales. Así, la figura de Perón lograría condensar ese otro común, ante el cual se oponen los diferentes sectores de la 
sociedad argentina a mediados de los cuarenta; 2) la constitución de una frontera que divide a la sociedad en dos campos antagónicos. Aquí, el campo peronista $y$ el antiperonista, simbolizado en los principios de lectura: democráticosnaziperonistas, antifascistas-fascistas, etc.; 3) la consolidación de una cadena de equivalencia que excede los lazos establecidos por la mera oposición a un exterior común. Donde según Bisso, los intereses particulares de los diferentes sectores serían relegados a los efectos de lograr esa eficaz consecución del fin primordial que traería beneficios absolutos para todos aquellos que se articulaban por fuera del campo peronista. Entonces, cabría preguntarse hasta qué punto no se puede profundizar en la movilización secundaria que Germani consideraba importante estudiar, pero no desde su propuesta teórica sino desde la construcción del pueblo como actor social colectivo.

\section{VI}

La lectura coloquial que se ha llevado a cabo sobre la conformación del espacio político no peronista ${ }^{12}$ posibilitó jugar con los tres textos presentados. Así, se retoma y discute algunos de los puntos en la lectura histórica que hace Bisso del antifascismo argentino con el fin de dejar abierto, para un examen más exhaustivo, otro camino interpretativo de esa movilización que Germani considera igualmente importante: el movimiento antiperonista. Precisamente, en diálogo con el argumento de Laclau, que encuentra en la construcción del pueblo la posibilidad de extender la noción de populismo a movimientos que no han sido identificados con esa categoría, se pretende dejar abierta una nueva posibilidad de interpretación.

Ahora, algunas preguntas suscitan la posibilidad de extender la noción de populismo si se tiene en cuenta el contexto histórico en el cual emerge el peronismo. Ya que, si este fenómeno es interpretado como la disputa del pueblo en oposición al poder de la oligarquía, pero la conformación del antiperonismo como

12 En tanto se es consciente de la pluralidad de dimensiones de análisis que se ha dejado de lado en el desarrollo de este argumento. espacio político también, se plantea en oposición a un poder dominante, cabría preguntarse: ¿cómo se define al poder dominante en la propuesta de Laclau?, ¿en relación con qué se determina su significación?, ¿tiene que ver con la instancia de decisión?; es decir, el aparato estatal. Porque la pluralidad de demandas insatisfechas que Laclau suele presentar como ejemplo, hacen referencia a la relación entre sectores sociales insatisfechos y Estado no satisfactor. En tal caso, ¿cómo se explica la constitución del peronismo como identidad populista, si no es precisamente el antiperonismo el que posee el control del aparato estatal? De la misma manera, cabría preguntarse ¿cómo se define a los de abajo?, ¿cuál es el pueblo?, o en última instancia, ¿pueden existir dos pueblos populistas contrapuestos? Porque si los autores presentados definen al peronismo como una experiencia populista y a su vez, el antiperonismo podría llegar a interpretarse como la construcción de un pueblo, ¿dónde se fijan los límites que establecen qué es el pueblo y qué es el poder?

Otra interrogante podría plantearse desde el lado de las demandas. Precisamente, cabría preguntarse: ¿cómo se determina la insatisfacción de una demanda? En otras palabras, ¿la insatisfacción se liga a la incapacidad del Estado para responder las pretensiones de cualquier espacio político? Podría argumentarse que las demandas pueden tener diferentes responsables de su insatisfacción, que no necesariamente tienen al poder estatal como aquel que imposibilita sus pretensiones. Ahora bien, ¿cómo esas demandas que tienen diferentes responsables de su insatisfacción pueden construir al pueblo como actor social colectivo? La respuesta es simple: porque hay una demanda que logra sobredeterminar la cadena de equivalencias que se constituye entre ellas en oposición a un poder. Así, se llega nuevamente a la pregunta acerca de ¿cómo se estipula, cuál es el poder?

Por otra parte, se podría preguntar ¿cómo se produce la división del campo social en dos partes? Supongamos que las demandas que tienen diferentes instancias causantes de su insatisfacción, logran construir al pueblo populista en oposición a un poder. Aquí, la pregunta es: ¿la división del espacio social la 
determina el pueblo populista? En relación con el caso de estudio, ¿son los peronistas o los antiperonistas los que abren una brecha en el interior de la sociedad argentina? Es decir, ¿es el antiperonismo o el peronismo el que establece la frontera que fractura el espacio social?

En otros términos, si el peronismo se constituyó como una demanda popular, ¿el antiperonismo también puede ser una demanda popular? Si la respuesta es negativa, ¿por qué las demandas de los sectores antiperonistas serían una demanda democrática y no una demanda popular? ya que en todo caso, el antiperonismo en su constitución también, dividiría el campo social en dos espacios antagónicos. Entonces, ¿cuál es la demanda que determina la división?, ¿quién sería el que fractura la armonía social? Si hay demandas populares y demandas democráticas, una que quiebra el campo social y la otra que no, entonces, ¿toda fractura también es ante un poder? De tal modo, se retoma la pregunta que plantea, si el poder es el aparato estatal. En tal sentido, repreguntarse por la figura del Estado no deja de ser una pregunta vigente $y$ con pocas respuestas en la teoría de Laclau.

Así, se ha dejado una pluralidad de respuestas abiertas en relación con la propuesta interpretativa que se plantea al comienzo del presente apartado; es decir, sobre la construcción de la identidad política antiperonista desde la extensión de la categoría de populismo sostenida por Laclau. Simplemente, la intención fue rastrear puntos a partir de los cuales se puede profundizar en dicha línea de investigación. Precisamente, dejar presentes algunos apuntes sobre la conformación del espacio político no peronista.

\section{BIBLIOGRAFÍA Y REFERENCIAS}

Bisso, Andrés. El antifascismo argentino. 1era edición. Argentina: CeDInCI, 2007.

De Ípola, Emilio. "Ruptura y continuidad. Claves parciales para un balance de las interpretaciones del peronismo". Desarrollo Económico 29 (115). IDES, octubre/diciembre 1989: 331-359.

Germani, Gino. Política y sociedad en una época de transición. De la sociedad tradicional a la sociedad de masas. 1era edición. Argentina: Paidós, 1965.

Germani, Gino. "El surgimiento del peronismo. El rol de los obreros y de los migrantes internos". Desarrollo Económico 13 (51). IDES, octubre/ diciembre 1973: 435-488.

Germani, Gino. Autoritarismo, fascismo y populismo nacional. 1era edición. Argentina: Temas, 2003.

Halperín Donghi, Tulio. "Algunas observaciones sobre Germani, el surgimiento del peronismo y los migrantes internos". Desarrollo Económico 14 (56). IDES, enero/marzo 1975: 765-781.

Laclau, Ernesto. Política e ideología en la teoría marxista. Capitalismo, fascismo y populismo. lera edición. Madrid: Siglo XXI, 1978.

Laclau, Ernesto. La razón populista. 1era edición. Argentina: Fondo de Cultura Económica, 2005a.

Laclau, Ernesto. "Populismo: ¿qué hay en el nombre?". En: Arfuch, Leonor. Pensar este tiempo. Espacios, afectos, pertenencias. 1era edición. Argentina: Paidós, 2005b.

Laclau, Ernesto. Debates y combates. Por un nuevo horizonte de la política. 1era edición. Argentina: Fondo de Cultura Económica, 2008.

Luna, Félix. El 45. Crónica de un año decisivo. lera edición. Argentina: Hyspamérica, 1971.

Murmis, Miguel y Portantiero, Juan Carlos. Estudios sobre los orígenes del peronismo. lera edición. Argentina: Siglo XXI, 1973.

Peña, Milcíades. El peronismo. Selección de documentos para la historia. 1era edición. Argentina: El Lorraine, 1986.

Potash, Robert. El ejército y la politica en la Argentina, 1928-1945: de Yrigoyen a Perón. lera edición. Argentina: Hyspamérica: 1969.

Rancière, Jacques. El desacuerdo. Política y filosofía. lera edición. Argentina: Nueva Visión, 1996. 
Torre, Juan Carlos. La vieja guardia sindical y Perón. 1era edición. Argentina: Sudamericana, 1990.
Fecha de ingreso: 13/06/2010

Fecha de aprobación: 19/07/2011 